\title{
Laparoscopic transdiaphragmatic chest surgery: Early experience
}

\author{
Rafael Santiago Andrade, MD, ${ }^{a}$ Ilitch Diaz-Gutierrez, MD, ${ }^{a}$ Jacob Hutchins, MD, ${ }^{b}$ Alexander Kaizer, PhD, \\ Joseph Small, MHA, ${ }^{\mathrm{d}}$ and Madhuri Rao, MD ${ }^{\mathrm{a}}$
}

\section{ABSTRACT}

Objective: We describe laparoscopic transdiaphragmatic (LTD) chest surgery without intercostal incisions and focus on technique and safety. The goal of LTD is to minimize postoperative pain.

Methods: We reviewed all patients undergoing LTD chest surgery (September 8, 2010-April 4, 2017). We place 4 abdominal ports with the patient in semilateral decubitus, make 2 diaphragmatic openings, and advance 2 ports into the chest. The intrathoracic operation is standard video-assisted thoracoscopic surgery (VATS), and diaphragmatic openings are closed at the end. We compared narcotic use (morphine equivalents) between patients undergoing LTD lung resection with historical controls undergoing conventional VATS.

Results: We performed 28 LTD chest procedures (wedge, 19; lobectomy, 3; segmentectomy, 3; other, 3; right sided, 20). Indications were lung nodule (14), lung cancer (5), interstitial lung disease (6), and other (3). Median operative times were 138 minutes (96-240 minutes) for wedge resection and 296 minutes (255356 minutes, including transcervical mediastinal lymphadenectomy) for anatomic resections. Respiratory complications occurred in 3 patients and other complications in 5 (total $8 ; 28.6 \%$ ). Computed tomography in 22 patients (79\%) at median 13 months (3-47 months) after surgery showed no diaphragmatic hernia. LTD chest surgery patients used less narcotics than conventional VATS without paravertebral block 24 to 48 hours postoperatively $(P=.039)$.

Conclusions: Early experience suggests that LTD chest surgery is feasible and safe on short- to midterm follow-up. The specific role of LTD chest surgery will require definition of patient selection criteria, further experience to reduce operative time, long-term follow-up, and prospective comparison with conventional VATS. (J Thorac Cardiovasc Surg 2018;155:1294-9)

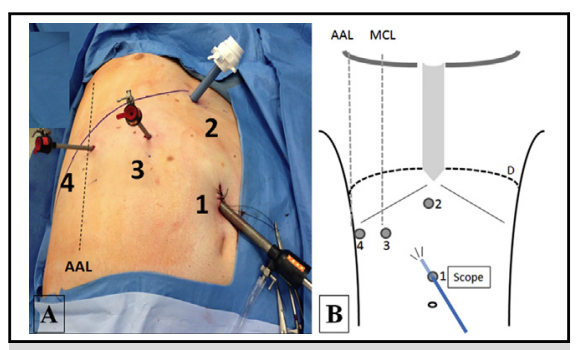

Laparoscopic transdiaphragmatic chest surgery port placement.

\section{Central Message}

Laparoscopic transdiaphragmatic chest surgery appears safe on short-term follow-up.

\section{Perspective}

Chest surgery without intercostal incisions will offer patients with chest diseases a potentially less painful alternative than transthoracic surgery. Laparoscopic transdiaphragmatic surgery offers yet another minimally invasive approach to tailor surgical care to the patient's individual characteristics.

See Editorial Commentary page 1300.
From the ${ }^{a}$ Division of Thoracic and Foregut Surgery, Department of Surgery, ${ }^{\mathrm{b}}$ Department of Anesthesiology, and ${ }^{\mathrm{d}}$ Clinical Databases, Division of Thoracic and Foregut Surgery, Department of Surgery, University of Minnesota, Minneapolis, Minn; and ${ }^{c}$ Department of Biostatistics and Informatics, University of Colorado, Aurora, Colo.

Institutional review board approval: an institutional review board exemption was obtained (STUDY00001037).

Read at the 97th Annual Meeting of The American Association for Thoracic Surgery, Boston, Massachusetts, April 29-May 3, 2017.

Received for publication May 8, 2017; revisions received Oct 13, 2017; accepted for publication Oct 26, 2017; available ahead of print Dec 14, 2017

Address for reprints: Rafael Santiago Andrade, MD, 420 Delaware St SE, Mayo Mail Code 207, Minneapolis, MN 55455 (E-mail: andro0119@umn.edu).

$0022-5223 / \$ 36.00$

Copyright (c) 2017 by The American Association for Thoracic Surgery

https://doi.org/10.1016/j.jtcvs.2017.10.127
We report an alternative approach to minimally invasive chest surgery avoiding intercostal incisions, because video-assisted thoracoscopic surgery (VATS) can lead to chronic neuropathic pain in $5 \%$ to $41 \%$ of patients. ${ }^{1}$ Our experience with laparoscopic diaphragm surgery ${ }^{2}$ helped us develop a laparoscopic transdiaphragmatic (LTD) approach to chest surgery, and we have previously reported a case of LTD thymectomy. ${ }^{3}$ This report describes our

Scanning this $\mathrm{QR}$ code will take you to a supplemental video. To view the AATS Annual Meeting Webcast, see the URL next to the webcast thumbnail.

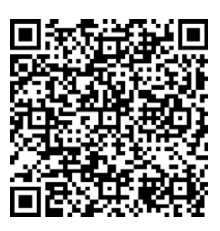




\section{Abbreviations and Acronyms \\ VATS $=$ video-assisted thoracoscopic surgery \\ LTD = laparoscopic transdiaphragmatic}

experience with LTD chest surgery and focuses on technique and safety.

\section{MATERIALS AND METHODS}

We obtained an institutional review board waiver for a retrospective review of our operative experience in patients who underwent LTD chest surgery from September 8, 2010, to April 4, 2017. We describe the surgical technique and evaluate indication, procedure type, operative time, complications, length of stay, and midterm to long-term imaging follow-up. To assess postoperative pain, a cohort of patients undergoing LTD lung resection chest surgery $(\mathrm{n}=24)$ was compared with a historical control group of patients undergoing conventional VATS without paravertebral block $(n=25)$ and with paravertebral block $(n=23)$. For our historical conventional VATS group, we used opioid and operative data from our prospective randomized trial of pain control in patients undergoing VATS with and without paravertebral catheter placement. $^{4}$

We use an Enhanced Recovery After Surgery pain management protocol for thoracic surgery patients at our institution. This includes acetaminophen, gabapentin, patient-controlled analgesia, and oral opioid analgesics. We routinely use local anesthetic ( $0.25 \%$ bupivacaine) for skin incisions and intraoperative intercostal nerve block. All patients in this group initially received hydromorphone intravenous patient-controlled analgesia for postoperative pain management.

\section{Data Collection and Statistical Analysis}

We retrospectively reviewed all patients undergoing LTD surgery and report operative and hospital data as median with range. Twenty-five patients underwent LTD lung resection chest surgery; however, 1 patient was excluded from analyses because of missing opioid data. We queried a prospectively collected opioid use database to determine opioid intake for each patient. We then converted oral and intravenous narcotics to morphine equivalents in milligrams for comparison and stratified the data in 4 different periods; intraoperative, postanesthesia care unit, 0 to 24 hours, and 24 to 48 hours. Opioid outcomes were not distributed normally $(P<.05$ for Shapiro-Wilk test for normality). Comparisons between the randomized groups therefore used the robust, nonparametric Kruskal-Wallis test. $P$ values are not adjusted for multiple comparisons and should be interpreted cautiously. All analyses were completed with $\mathrm{R}$ version 3.3.1 software.

Follow-up included a routine clinic visit at 3 to 4 weeks after discharge. Treating clinicians dictated the long-term clinical and radiologic follow-up at their discretion, as required by specific patient and disease characteristics.

\section{Procedure}

We use a double-lumen endotracheal tube and place the patient in a semilateral decubitus position (Figure 1). We place 4 abdominal ports (Figure 2, $A$ and $B$ ) as follows:

- Port 1 (5 or $12 \mathrm{~mm})$ is supraumbilical.

- Port $2(12 \mathrm{~mm})$ is subxiphoid,

- Port $3(5 \mathrm{~mm})$ is on the subcostal midclavicular line.

- Port $4(5 \mathrm{~mm})$ is on the subcostal anterior axillary line.

We use laparoscopy (carbon dioxide insufflation of $15 \mathrm{~mm} \mathrm{Hg}$; Figure 3 and Figure $4, A$ and $B$ ) to make 2 small anterior diaphragmatic openings

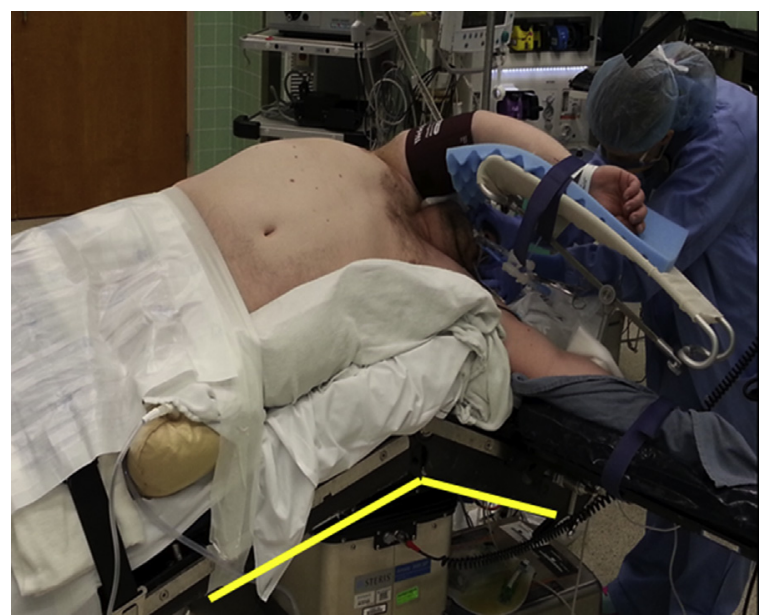

FIGURE 1. Patient in semilateral position for right laparoscopic transdiaphragmatic chest surgery. The yellow line highlights the flexion of the operating table.

that eventually allow intrathoracic placement of the 2 subcostal ports (ports 3 and 4). After we have made the openings, we place a pledgeted 2-0 nonabsorbable $U$ stitch around each opening for eventual closure. Next, we advance the subcostal ports through the diaphragmatic openings into the chest (Figure 4, B, and Figure 5), vent the pneumoperitoneum through the supraumbilical port (port 1), and insufflate through the chest with carbon dioxide at a pressure of 10 to $12 \mathrm{~mm} \mathrm{Hg}$. Once we have advanced a scope through one of the subcostal transdiaphragmatic ports (ports 3 and 4), we can advance the subxiphoid port (port 2) retrosternally into the chest under direct vision. At this point, we have 3 intrathoracic ports, and the procedure proceeds in a manner akin to standard VATS (Figure 6, $A$ and $B$ ). Briefly, for anatomic resections, we perform the mediastinal lymph node dissection first, starting with the subcarinal lymph nodes. The subcarinal dissection is the most challenging, because the posterior chest cavity is the furthest from the ports. During the subcarinal dissection, we also dissect the posterior aspect of the airway. After completion of the posterior dissection, we proceed with the anterior dissection. First, we dissect the remainder of N2 stations and all N1 lymph nodes surrounding the bronchovascular structures of the lobe or segment to be removed. Second, once the N1 lymph node dissection is complete, we can safely dissect and transect the bronchovascular structures and complete the parenchymal division.

At the end of the procedure, we remove the specimen through the subxiphoid port (either with a specimen pouch or through a wound protector) and place a chest tube through the subxiphoid port. We next pull the 2 subcostal transdiaphragmatic ports (ports 3 and 4) back into the abdomen and insufflate the abdomen. We then finish suturing the previously placed diaphragmatic $U$ stitches to close the 2 small diaphragmatic openings (Figure 7) and conclude with the closure of the laparoscopic incisions (Video 1).

\section{RESULTS}

During the study period, we performed 28 LTD chest procedures: wedge resection $(\mathrm{n}=19)$, lobectomy $(\mathrm{n}=3)$, segmentectomy $(\mathrm{n}=3)$, and other $(\mathrm{n}=3)$. Anatomic resections included left segment $6(\mathrm{n}=1)$, right segment $6(\mathrm{n}=2)$, left lower lobe $(\mathrm{n}=1)$, right middle lobe $(\mathrm{n}=1)$, and right lower lobe $(\mathrm{n}=1)$. Indications for surgery were lung nodule $(n=14)$, lung cancer $(n=5)$, interstitial 

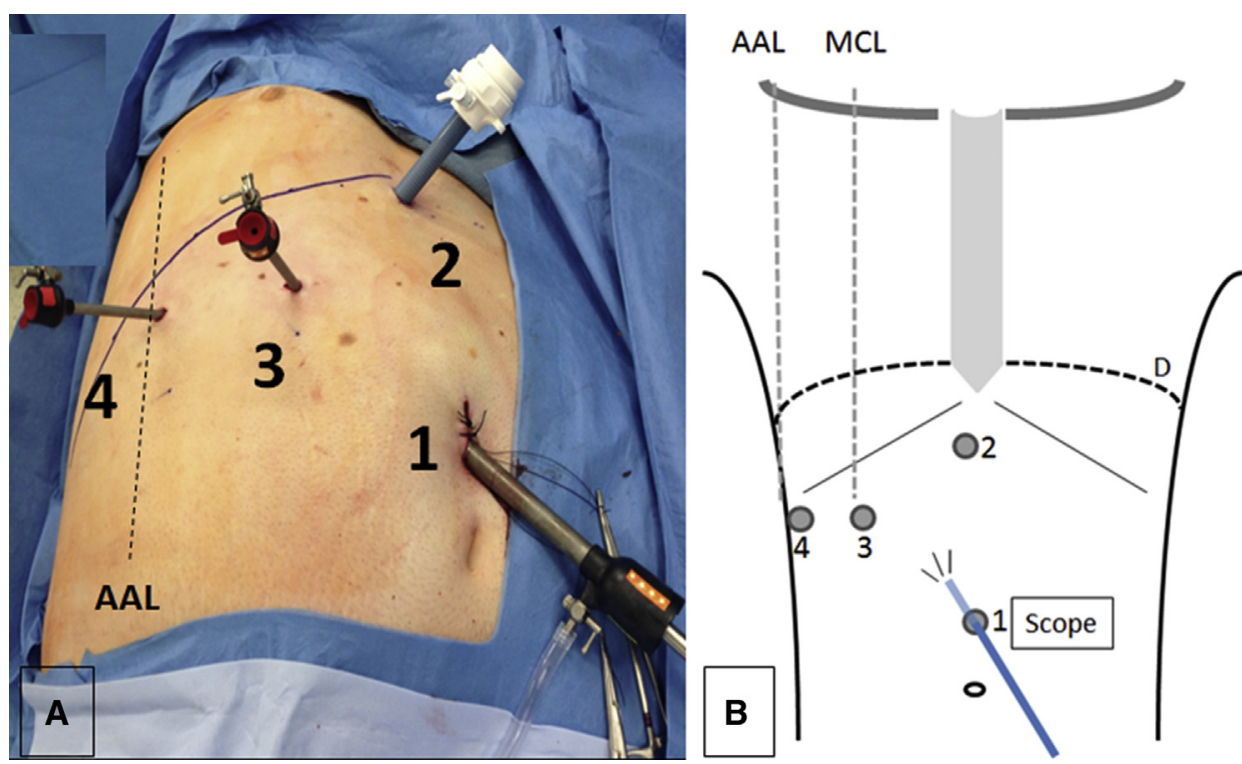

FIGURE 2. A, Port placement for right laparoscopic transdiaphragmatic chest surgery. Port 1 is supraumbilical, port 2 is subxiphoid, port 3 is subcostal (midclavicular line $[M C L]$ ), and port 4 is subcostal (anterior axillary line $[A A L]$ ). B, Schematic representation of port placement for right laparoscopic transdiaphragmatic chest surgery. $D$, Diaphragm.

lung disease $(n=6)$, and other $(n=3$; pleural nodule, $n=2$, and mediastinal mass, $\mathrm{n}=1$ ). Twenty procedures were right sided, and 8 were left sided. All nodules were peripheral and $3 \mathrm{~cm}$ or smaller in size. We performed additional procedures in 6 patients $(21 \%)$ : laparoscopic hiatal hernia repair (with or without Nissen fundoplication) in 3 and other laparoscopic procedures in 3 . In 3 patients who underwent a planned anatomic resection for lung cancer, we performed a transcervical extended mediastinal lymphadenectomy at the beginning of the case, but we include the transcervical extended mediastinal lymphadenectomy operative time as part of the anatomic lung resection. Table 1 summarizes types of procedures, blood loss, operative times, conversions to a transthoracic approach, respiratory complications, and lengths of stay. No patient required a blood transfusion.

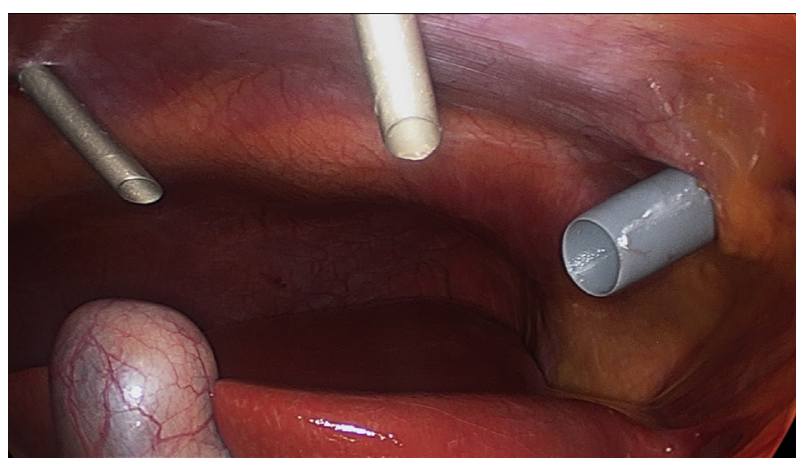

FIGURE 3. Laparoscopic view through the supraumbilical port (port 1) of the diaphragm, the subxiphoid port, and the subcostal ports.
Of the patients who underwent LTD surgery, $8(28.6 \%)$ had complications: 2 had prolonged air-leak ( $\geq 5$ days), 1 (a young male patient with cognitive impairment who could not cooperate with pulmonary toilet) had atelectasis requiring bronchoscopy, 3 had urinary retention, 1 had

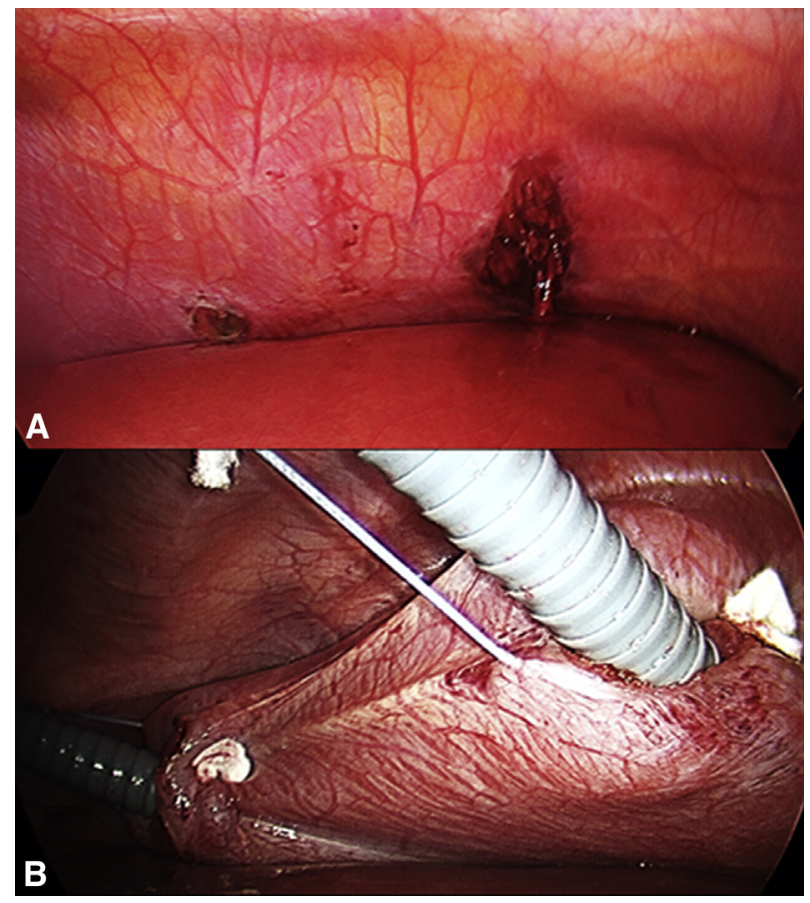

FIGURE 4. A, Two anterior diaphragmatic openings for subcostal ports. B, Subcostal ports have been advanced transdiaphragmatically into the chest cavity. The stitches help keep the ports in place. 


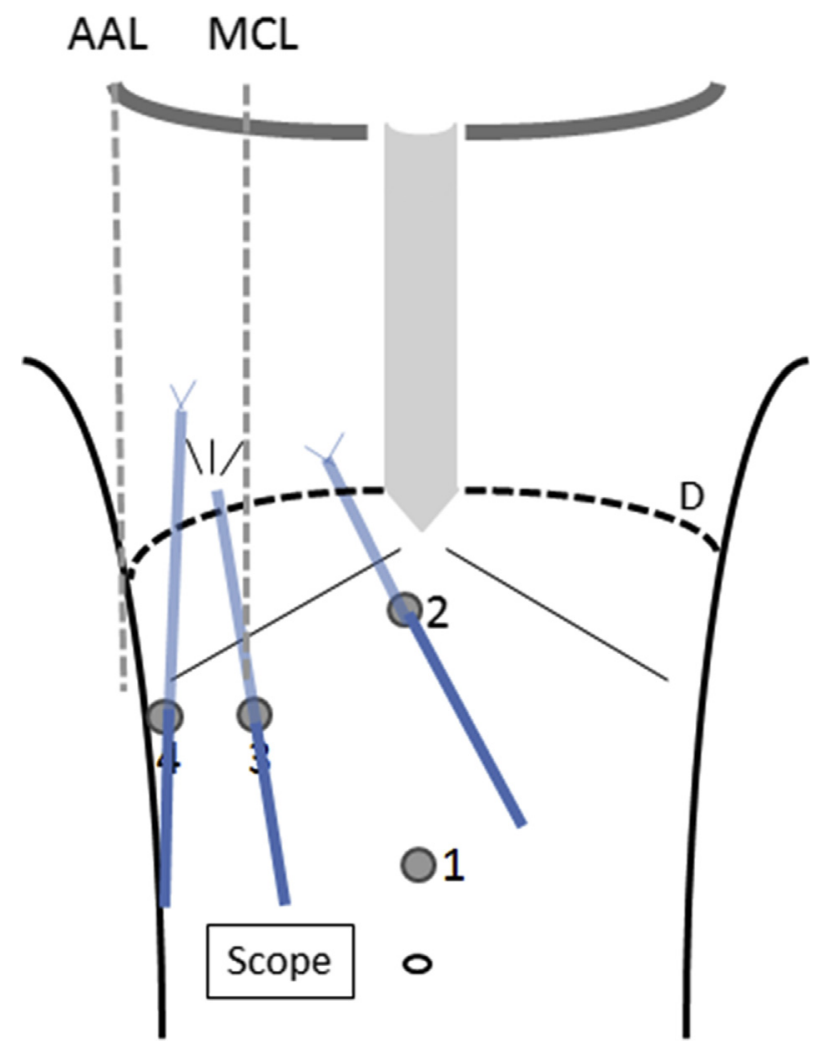

FIGURE 5. Schematic representation of transdiaphragmatic placement of ports. The subcostal ports (ports 3 and 4) and the subxiphoid port (port 2) have been advanced into the chest. The scope is now placed through one of the subcostal ports, and the supraumbilical port vents the pneumoperitoneum. $A A L$, Anterior axillary line; $M C L$, midclavicular line; $D$, diaphragm.

delirium, and 1 had constipation requiring readmission. No patient had complications that required a return to the operating room.

Of the patients who underwent LTD surgery, $22(79 \%)$ had follow-up computed tomography at a median of 13 months (3-47 months) after surgery without evidence of diaphragmatic hernia. The remaining 6 patients did not have follow-up imaging (death from advanced disease,

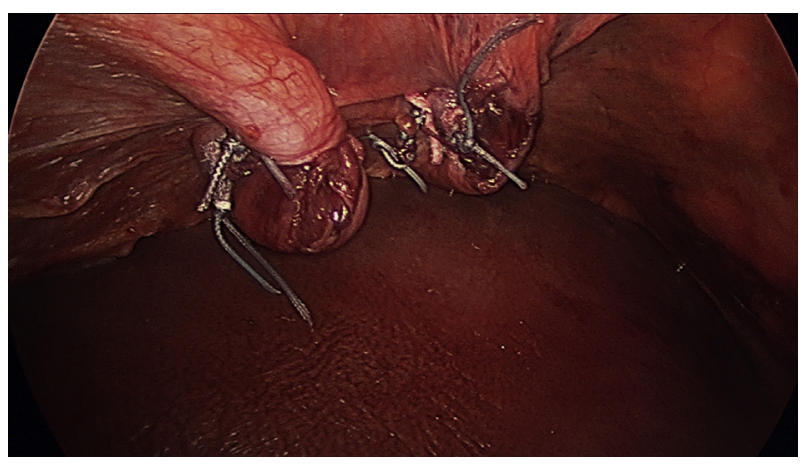

FIGURE 7. Diaphragmatic closure.

$\mathrm{n}=1$; unavailability for follow-up, $\mathrm{n}=2 ;<3$ months after surgery, $\mathrm{n}=3$ ).

\section{Pain Control}

Table 2 summarizes our comparison of operative data between the cohorts of patients undergoing LTD chest surgery and patients undergoing conventional VATS. Patients undergoing LTD chest surgery had significantly less morphine equivalents than did those undergoing conventional VATS without paravertebral block 24 to 48 hours after surgery $(P=.039$; Table 3$)$. We did not identify any other significant differences in opioid use between patients undergoing LTD surgery and those undergoing VATS (Table 3).

\section{DISCUSSION}

Our report describes an alternative minimally invasive approach to chest surgery that avoids intercostal incisions. To date, we can only report on operative details and shortterm to midterm safety. We cannot yet decide what exact role this approach may eventually play within the spectrum of minimally invasive thoracic surgery procedures.

The evolution of our technique occurred gradually and was based on our experience with laparoscopic diaphragm surgery. ${ }^{2}$ Our previous familiarity with laparoscopic diaphragm surgery helped us realize that the pulmonary

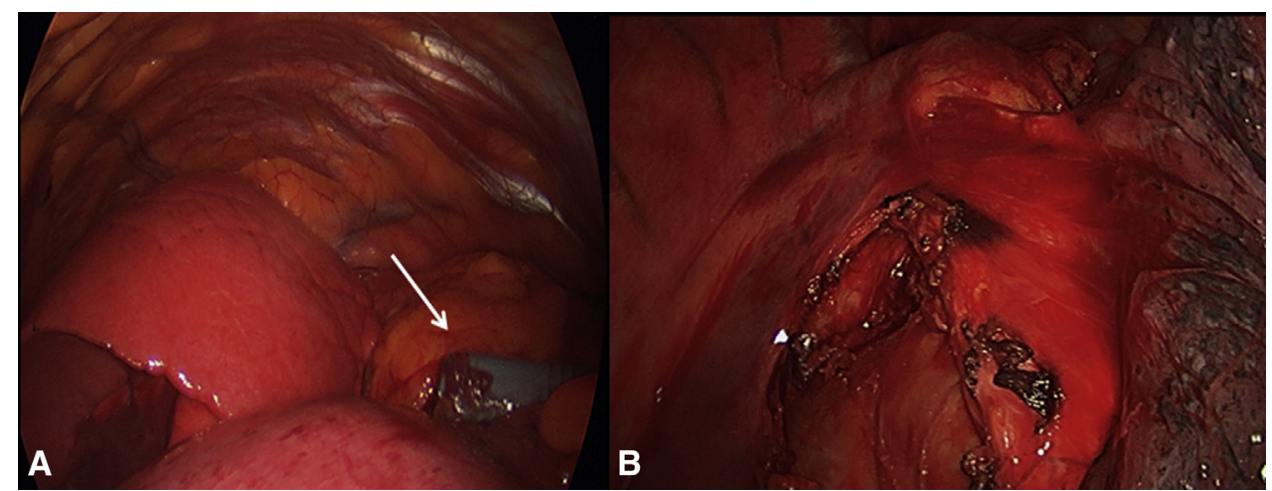

FIGURE 6. A, Transdiaphragmatic thoracoscopic view of the right pleural space. Arrow indicates subxiphoid port as seen from 1 of the subcostal transdiaphragmatic ports. B, Transdiaphragmatic thoracoscopic view of the subcarinal space after lymph node dissection. 


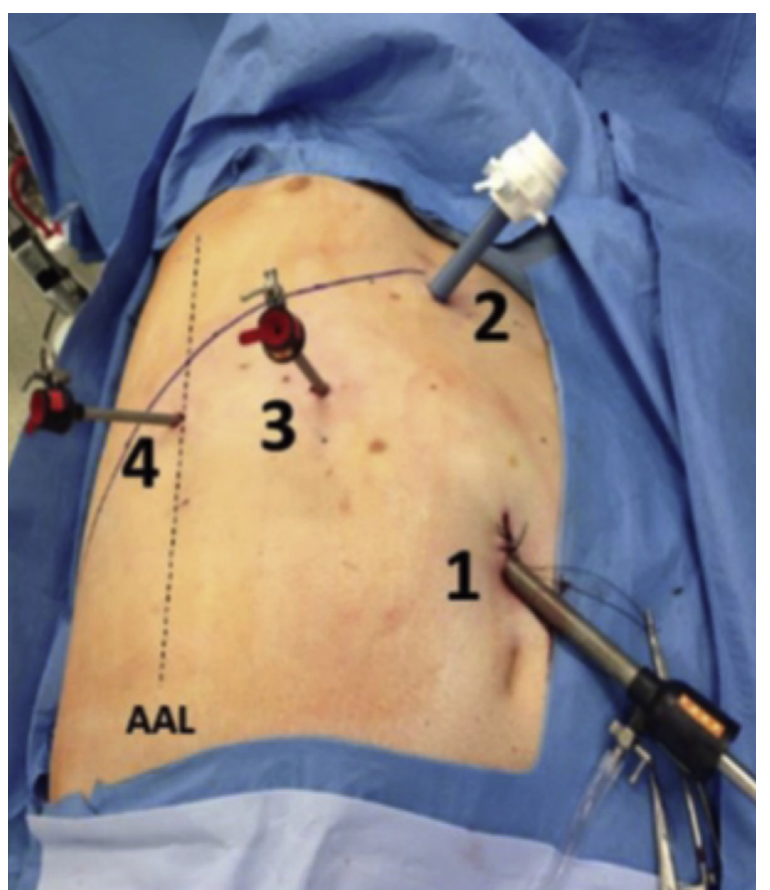

VIDEO 1. Laparoscopic transdiaphragmatic right lower lobe wedge resection. AAL, Anterior axillary line; VATS, video-assisted thoracoscopic surgery. Video available at: http://www.jtcvsonline.org/article/S00225223(17)32476-5/fulltext.

hilum and the anterior chest cavity are easily visible and accessible through the diaphragm, and we have previously described our technique of LTD thymectomy. ${ }^{3}$ To date, only 1 additional case report has been published that describes a similar technique for resection of a paraganglioma. ${ }^{5}$ The purely subxiphoid technique for chest surgery has gradually gained popularity, and several reports of lung and thymus resections have been published to date. ${ }^{5-13}$ Currently, we favor the LTD approach, because we believe that it offers more freedom of movement, allows insufflation of the thoracic cavity, and is technically easier for us than the purely subxiphoid approach.

As a result of our operative experience, we have cautiously selected our patients and tend to avoid the LTD approach in patients with central obesity; that is, in patients with a body mass index of $35 \mathrm{~kg} / \mathrm{m}^{2}$ or greater. In addition, we favor a transthoracic approach to the lower lobes and the posterior aspect of the chest cavity. We avoid the left transdiaphragmatic approach in young patients or patients
TABLE 2. Comparison of operative data between patients undergoing laparoscopic transdiaphragmatic chest surgery, patients undergoing video-assisted thoracoscopic surgery without paravertebral block, and patients undergoing video-assisted thoracoscopic surgery with paravertebral block

\begin{tabular}{|c|c|c|c|}
\hline Covariate & $\begin{array}{l}\text { LTD chest } \\
\text { surgery } \\
(\mathrm{N}=\mathbf{2 4})\end{array}$ & $\begin{array}{l}\text { No block } \\
(N=25)\end{array}$ & $\begin{array}{c}\text { Paravertebral } \\
\quad(\mathbf{N}=\mathbf{2 3})\end{array}$ \\
\hline \multicolumn{4}{|l|}{ Procedure } \\
\hline Wedge & $17(70.8 \%)$ & $20(80.0 \%)$ & $17(73.9 \%)$ \\
\hline Segmentectomy & $2(8.3 \%)$ & $1(4.0 \%)$ & $0(0.0 \%)$ \\
\hline Lobectomy & $2(8.3 \%)$ & $3(12.0 \%)$ & $5(21.7 \%)$ \\
\hline Other & $3(12.5 \%)$ & $1(4.0 \%)$ & $1(4.3 \%)$ \\
\hline Right lung indicator & $19(79.2 \%)$ & $12(48.0 \%)$ & $15(65.2 \%)$ \\
\hline Procedure time (min) & $183 \pm 78.6$ & $202 \pm 84.7$ & $185 \pm 56.5$ \\
\hline PACU time (min) & $148 \pm 61.6$ & $144 \pm 62.5$ & $161 \pm 68.5$ \\
\hline $\mathrm{EBL}(\mathrm{mL})$ & $43.1 \pm 65.9$ & $50.6 \pm 86.2$ & $45.8 \pm 68.8$ \\
\hline
\end{tabular}

Data are presented as N (\%) or mean \pm SD. LTD, Laparoscopic transdiaphragmatic; $P A C U$, postanesthesia care unit; $E B L$, estimated blood loss.

who routinely do heavy lifting. To date, however, we have not clearly defined inclusion and exclusion criteria for LTD chest surgery.

As we gained experience, we reduced the operative time. The shortest time was 96 minutes for a wedge resection. In addition to our learning curve, we have also been extremely cautious in our approach, which has undoubtedly lengthened our operations. We are not satisfied with our operative times, however, and we think that we will be able to reduce operating room time further by placing the subcostal ports extraperitoneally.

Our results suggest that the LTD approach to chest surgery is safe in the short-term to midterm. We have not had any intraoperative complications, no patients have required a transfusion or return to the operating room, and all postoperative complications have been reversible and not life-threatening. Midterm to long-term follow-up with computed tomographic imaging has not yet demonstrated any diaphragmatic hernias, with a median of 13 months of follow-up after LTD surgery. These findings are consistent with our laparoscopic diaphragm surgery experience. ${ }^{2}$

Our original purpose in developing a minimally invasive technique that avoids intercostal incisions was to optimize acute and chronic postoperative pain management. The reported incidence of chronic pain after VATS ranges

TABLE 1. Summary of operative details of 28 laparoscopic transdiaphragmatic chest procedures

\begin{tabular}{lrccccc}
\hline \multicolumn{1}{c}{ Procedure } & N & EBL $(\mathbf{m L})^{*}$ & OR time $(\mathbf{m i n}) *$ & Conversion & Respiratory complications* & LOS $(\mathbf{d}) *$ \\
\hline Anatomic resection $\dagger$ & 6 & $175(50-500)$ & $296(255-356) \ddagger$ & Open $(\mathrm{n}=1)$, VATS $(\mathrm{n}=1)$ & Air leak $(\mathrm{n}=2)$, atelectasis $(\mathrm{n}=1)$ & $3.5(2-8)$ \\
Wedge resection and other $\S$ & 22 & $15(5-50)$ & $138(96-240)$ & 0 & 0 & $1.5(0-7)$ \\
\hline
\end{tabular}

$E B L$, Estimated blood loss; OR, operating room; LOS, length of stay; VATS, video-assisted thoracoscopic surgery. *Stand-alone procedure. $\nmid$ Lobectomy, segmentectomy. $\ddagger$ Includes transcervical extended mediastinal lymphadenectomy time in 3 cases. §Pleural nodule $(\mathrm{n}=2)$, mediastinal mass $(\mathrm{n}=1)$. 
TABLE 3. Kruskal-Wallis test results comparing opioid use between patients undergoing laparoscopic transdiaphragmatic chest surgery, patients undergoing video-assisted thoracoscopic surgery with no paravertebral block, and patients undergoing video-assisted thoracoscopic surgery with paravertebral block

\begin{tabular}{lclc}
\hline Covariate & $\begin{array}{c}\text { LTD chest } \\
\text { surgery } \\
(\mathbf{N}=\mathbf{2 4})\end{array}$ & $\begin{array}{c}\text { No block } \\
(\mathbf{N}=\mathbf{2 5})\end{array}$ & $\begin{array}{c}\text { Paravertebral } \\
(\mathbf{N}=\mathbf{2 3})\end{array}$ \\
\hline Intraoperative & $30.8(15-62)$ & $30.0(10-75)$ & $28.3(10-57)$ \\
PACU & $8.3(0-27)$ & $15.3(0-38)$ & $14.0(0-49)$ \\
\hline $0-24 \mathrm{~h}$ & $21.2(2-60)$ & $26.7(3-146)$ & $21.7(3-106)$ \\
$24-48 \mathrm{~h}$ & $15.0(0-126) *$ & $24.2(5-171)^{*}$ & $7.5(0-87)$ \\
\hline
\end{tabular}

Data are presented as median and range in morphine equivalents (mg). LTD, Laparoscopic transdiaphragmatic; $P A C U$, postanesthesia care unit. $* P=.039$ between laparoscopic transdiaphragmatic chest surgery and no block.

between $5 \%$ and $41 \%,{ }^{1}$ which is not insignificant. Our retrospective comparison of opioid use between patients undergoing LTD surgery and conventional VATS suggests a significant decrease in early opioid requirements in those undergoing LTD surgery. Nonetheless, we were not able to find a difference in opioid requirements when comparing patients undergoing LTD surgery with those undergoing VATS with a paravertebral catheter. We interpret these results cautiously, because the sample sizes are very small, and the analysis is retrospective. At this point, we are reluctant to draw a conclusion regarding postoperative pain control in patients undergoing LTD surgery versus those undergoing VATS. Only a prospective, randomized trial will help us address this question with more certainty.

Although there are no similar studies in the literature, a comparative, albeit retrospective, study of subxiphoid versus VATS thymectomy by Suda and colleagues ${ }^{9}$ suggests that patients after subxiphoid thymectomy use less narcotic pain medications than patients after VATS thymectomy.

Limitations to this study include a small number of patients, limited midterm to long-term follow-up, and a retrospective comparison of patients undergoing LTD surgery with those undergoing VATS.

We conclude that LTD chest surgery can be performed safely and may add to the minimally invasive surgical options for patients requiring chest surgery. Currently, we are not sure of the final role that this approach could play in thoracic surgery. Nonetheless, we are of the opinion that cautiously exploring innovative minimally invasive surgical techniques allows us to make progress in our field and to tailor procedures to individual patients' needs.

\section{Webcast}

You can watch a Webcast of this AATS meeting presentation by going to: https://aats.blob.core.windows.net/ media/17AM/2017-05-02/RM302-304/05-02-17_Room 302-304_0758_Santiago_Andrade.mp4.

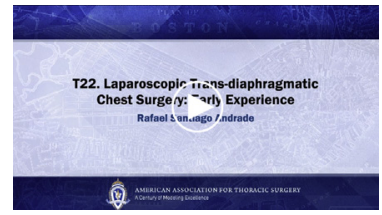

\section{Conflict of Interest Statement}

Dr Hutchins is a consultant, is a speaker, and receives research support from Pacira Pharmaceuticals; is a consultant for Halyard Health and Worrell; and is a consultant and stock owner of Insitu Biologics. All other authors have nothing to disclose with regard to commercial support.

\section{References}

1. Maguire MF, Ravenscroft A, Beggs D, Duffy JP. A questionnaire study investigating the prevalence of the neuropathic component of chronic pain after thoracic surgery. Eur J Cardiothorac Surg. 2006;29:800-5.

2. Groth SS, Rueth NM, Kast T, D'Cunha J, Kelly RF, Maddaus MA, et al. Laparoscopic diaphragmatic plication for diaphragmatic paralysis and eventration: an objective evaluation of short-term and midterm results. $J$ Thorac Cardiovasc Surg. 2010;139:1452-6.

3. Aziken N, Evasovich M, Andrade RS, Podgaetz E. Laparoscopic transdiaphragmatic thymectomy without chest incisions. Eur J Cardiothorac Surg. 2016;51:385-7

4. Hutchins J, Sanchez J, Andrade R, Podgaetz E, Wang Q, Sikka R. Ultrasound-guided paravertebral catheter versus intercostal blocks for postoperative pain control in video-assisted thoracoscopic surgery: a prospective randomized trial. J Cardiothorac Vasc Anesth. 2017;31:458-63.

5. Sunose Y, Hirai K, Nakazawa S, Yoshinari D, Ogawa H, Tsukagoshi H, et al. Laparoscopic resection of a paraganglioma located on the border of the thoracic and abdominal cavities using a transabdominal-transdiaphragmatic approach. Asian J Endosc Surg. 2015;8:201-4.

6. Yano M, Moriyama S, Haneda H, Okuda K, Kawano O, Oda R, et al. The subxiphoid approach leads to less invasive thoracoscopic thymectomy than the lateral approach. World J Surg. 2017;41:763-70.

7. Zieliński M, Kużdżał J, Szlubowski A, Soja J. Transcervical-subxiphoidvideothoracoscopic "maximal" thymectomy-operative technique and early results. Ann Thorac Surg. 2004;78:404-9.

8. Gonzalez-Rivas D, Yang Y, Lei J, Hernandez L, Jiang G. Subxiphoid uniportal video-assisted thoracoscopic middle lobectomy and anterior anatomic segmentectomy (S3). J Thorac Dis. 2016;8:540-3.

9. Suda T, Hachimaru A, Tochii D, Maeda R, Tochii S, Takagi Y. Video-assisted thoracoscopic thymectomy versus subxiphoid single-port thymectomy: initial results. Eur J Cardiothorac Surg. 2015;49(Suppl 1):154-8.

10. Jiang L, Liu J, Shao W, Li J, He J. Non-intubated subxiphoid uniportal video-assisted thoracoscopic thymectomy using glasses-free 3D vision. J Thorac Dis. 2016;8:E1602-4.

11. Wang BY, Chang $\mathrm{YC}$, Chang $\mathrm{YC}$, Wang $\mathrm{KM}$, Lin $\mathrm{CH}$, Lin $\mathrm{SH}$, et al. Thoracoscopic surgery via a single-incision subxiphoid approach is associated with less postoperative pain than single-incision transthoracic or three-incision transthoracic approaches for spontaneous pneumothorax. J Thorac Dis. 2016; 8(Suppl 3):S272-8.

12. Wu L, Lin L, Liu M, Jiang L, Jiang G. Subxiphoid uniportal thoracoscopic extended thymectomy. J Thorac Dis. 2015;7:1658-60.

13. Liu CC, Wang BY, Shih CS, Liu YH. Subxiphoid single-incision thoracoscopic left upper lobectomy. J Thorac Cardiovasc Surg. 2014;148:3250-1.

Key Words: laparoscopy, VATS, diaphragm, lung, lung neoplasms, pain, narcotics 